\title{
A MOBILE SMART EMERGENCY RESPONSE SYSTEM FOR JEDDAH CITY
}

\author{
Sahar Al-Dhaheri, Amal Alhassan, Weam Alazahrani, Khadijah Alfadli, Dr.Maram Meccawy \\ Faculty of Computing and Information Technology, Department of Information Systems King Abdulaziz \\ University, Kingdom of Saudi Arabia, Jeddah ${ }^{1,2,3,4,5}$
}

\begin{abstract}
Responding to disasters and crises is a crucial role for the government to ensure the public safety of society. Responding lies in the counter of crimes of civil or disorders, providing the urgent medical care to injured or sick people, and providing relief of natural and manmade disasters. Despite ongoing attempts to improve emergency response systems in Jeddah, Saudi Arabia, it still suffers from vulnerability. With the current development of the technology and internet of things (loT), it became necessary to apply these techniques for improving emergency response systems in Jeddah. In this paper, we present Jeddah Smart Emergency Response System (JSERS) as a solution to improve the emergency response system in Jeddah using smart city technologies j First, we discussed the problems related to the response to accidents and disasters and their history in the Kingdom of Saudi Arabia, especially Jeddah. Consequently, we described the proposed solution, followed by the architecture of the system. Following by the opportunities and the challenges of system implementation are discussed. Finally, a list of suggestions that supports this system implementation and deployment is reported.
\end{abstract}

\section{Indexing terms/Keywords}

Internet of things (IOT), Jeddah smart emergency response system (JSERS), smart city, digital city, e-government.

\section{Academic Discipline and Sub-Disciplines}

Information Systems; e-Government; Smart devices; Information society, Mobile Technologies.

\section{SUBJECT CLASSIFICATION}

Smart City

\section{TYPE (METHOD/APPROACH)}

A prototypic emergency response system for the city of Jeddah based on smart city and internet of things technologies..

\section{INTRODUCTION}

A Smart City is an urban environment which is supported by pervasive information and a communications technology (ICT) system, that has the ultimate goal for any city - smart or otherwise - which is to make an environment where persons can live without worrying about safety. There is no universally accepted definition of the concept Smart City (SC). According to the Gartner, it is "an urbanized area where multiple sectors cooperate to achieve sustainable outcomes through the analysis of contextual, real-time information shared among sector-specific information and operational technology system"[1]. They promise clean environment, better IT capabilities, better health care and education systems, and smart energy consumption models. Smart Cities have different fields of concern, like the Energy, public transport, and public safety. Regarding to ensuring public safety for the community is one of the critical responsibilities of the governments. Where the governments can provide Public safety by working in many central areas like Crime investigation, reduction and prevention Transportation/traffic services Disaster prevention mechanism. Certainly, one of Gartner's most new reports evaluates that SC will account for more than 9.7 billion Internet of Things (IoT) items by 2020[1]. These small devices can enhance public safety in a smart city by deploying the emergencies response system (ERS).

In this paper, we propose Jeddah Smart Emergency Response System (JSERS) to improve the emergency response system in Jeddah using smart city technologies. Section (1) discusses the problems which require an emergency response in Saudi Arabia. Section (2) reviews several cases of response to the emergency that have been implemented and studied in the literature in Saudi Arabia, especially Jeddah. Section (3) explains the problem statement. While section (4) describes the proposed solution and the architecture of Jeddah Smart Emergency Response System (JSERS) is presented in section (5). The opportunities from (JSERS) implementation and challenges are reported in sections (6, 7). Finally, the implementation of (JSRES) is described in section (8), and the suggestions which support an implementation and deployment of (JSERS) is discussed in (9) followed by the conclusion in section (10).

\section{BACKGROUND}

The smart city concept enables governments to provide critical services to their fast-growing population in the future. The smart cities need to leverage range of technologies to deliver a broad range of essential services. Emergency response represents the most important service can provide by the government. Responding to the crimes of civil or disorders, providing the urgent medical care to injured or sick people, and providing relief of natural and manmade disasters ( or hazards). Hazard is a potential risk that threatens the people in their lives and the environment. It called an emergency state if that risk leads to an incident or a disaster in case the damage is massive. During the last few decades, Saudi Arabia has experienced frequent disasters. The Major hazards can be classified into: 
- Road Traffic Accidents (RTAs): according to The World Health Organization's (WHO), the road traffic is one of the top 10 causes of death in Saudi Arabia with death rate 24.8 per 100.000 populations [2].

- Ramadan and Hajj: In 2015, stampede incident occurs in Mina, according to the government of Saudi Arabia over 717 people have been crushed to death and 934 others with Injuries. The disaster comes after two weeks of collapsed the construction crane onto Al-Masjid al-Haram and killing 111 people and injuring 394 [3].

- Terrorist Attacks: since 2001, the kingdom has been attacked 128 terrorist crimes which lead to the death and injury of 1,147 people[4]

- Fire: last year, the fires incidents in Saudi Arabia reached 51,781, with an average of six fires per hour [5].

- Natural disaster: such as earthquakes, dust storms and floods or flash flood (causing from poor drainage systems). From 1900 to 2010, Floods cause of 7 out of the ten major disasters in Saudi Arabia [6]. Jeddah As an example, the major two flash floods occurred in Jeddah during 2009 and 2011 which had highly impact. In 2009, 113 people were killed and caused damage to infrastructure and property (around 10000 homes and 17000 vehicles) [7].

All these incidents which occurred in the last 10-15 years indicating the importance of having a more effective emergency response system that utilizes the latest technologies and hence the need to apply smart cities concepts.

\section{RELATED WORK}

As mentioned earlier, Saudi Arabia has a rich history in hazards and emergencies that affected the people and country's resources. As different disasters occurred, the Kingdom has undertaken various proactive and reactive emergency response techniques and policies to minimize the losses caused by such disasters. We reviewed several cases of disaster response that have been implemented and studied in the literature about emergency management in Saudi Arabia. After the increase in terrorist attacks, the government designated emergency hotline, email, and fax number to report any suspicious persons might threaten national security.

Furthermore, to decrease the number of RTAs, a digital traffic control system called Saher has been introduced. Saher uses a network of digital cameras that inform the National Information Center of the Ministry of Interior about the traffic issues. These cameras coverage all roads in the cities within 24 hours a day [8]. In order to improve the emergency services for cars accident, another system was proposed but yet does not implement. The system has built based on Google map application for traffic detection and Global System for Mobile Communication (GSM) with a continuous update and wireless connection. In case an accident has occurred, when the survivor or any near person call the emergency service provider the GSM technology will track the caller location and alert all of ambulance, hospital, police and insurance agents. To facilitate reach to accident site, they decide the best routes based on information in Google map based on road traffic and distance [9]

However, finding the manners and means to mitigate the disaster are representing an urgent need to sustain Saudi Arabia resources. Disaster awareness and preparedness are two critical parameters can reduce its future impact [10]. As far as managing for medical evacuation in the Hajj season, a new system of aero-medical helicopters has implemented by the Saudi Red Crescent Society to facilitate better and fast response to the emergency situations [8]. Additionally, remote sensing and Geographic Information Systems (GIS ) techniques help to identify the areas in Saudi Arabia that are more susceptible to hazard. GIS improve ability to assess and monitor the disaster with a platform for register and manage the information [10].

Moreover, an emergency system named "Emergency Call and Operation Center" (ECO) has used in the Ministry of Interior's Program to improve the public safety and enhance the response to emergency scenarios. The ECO Centers are connected through extensive networks which provide multi-agency reporting for the Public Security Directorate and the Civil Defense [11]. Finally, to save lives and increase the efficiency of the emergency response, flood sensing system was proposed for Jeddah flood in 2009 using simulation. The system based on Unmanned Aerial Vehicles (UAV) equipped with mobile micro sensors to sensing the floods in real time [12,13].

Human's desire to prevent the occurrence of hazards is as old as man himself. Although Jeddah city emergency response systems have advanced a long way with the hazards discussed previously, it still has certain vulnerabilities. With the increase of population and accumulate of vehicles; Jeddah city has become a pool of risks. Many of responses to the emergency situations had been a result of trial and error and ad-hoc solutions which cost lives and waste resources. In order to enhance the response system, Jeddah city has to take advantage of new technologies and available tools. Furthermore, move to the next level through integration of Cyber-Physical Systems (CPS) components. CPS is "a new generation of systems with integrated computational and physical capabilities that can interact with humans through many new modalities"[14].

\section{JSERS: A UNIFIED APPROACH FOR EMERGENCY RESPONSE IN JEDDAH}

Based on the context of SmartAmerica Challenge 2013-2014, we suggest our solution. The idea behind Jeddah Smart Emergency Response System (JSERS) is to handle reporting incidents to the involved parties and coordinate their collaboration to ensure the most efficient and proper response, instead of the traditional call centers that introduce so many delays and ask for a bystander to be there at the time of the incident to report and describe the situation accurately. JSERS will not replace the call centers but will live as a complement [15]. JSERS provide the emergency staff with information about the location and the condition of the disaster and submit help requests from the survivors. Also, it is supported by real-time simulation technology across the wireless network technology and provides danger warning over geographic areas which 
cover Jeddah city [16]. To implement the proposed system, it is necessary to transfer the technology through collaboration with General Directorate of Civil Protection (GDCP) in Jeddah. Coordinate with the government institutions and sectors to intervention in the disasters cases. Arrange and implement plans which fit with the civil defense's rules and regulations to support the implementation of the proposed system.

\section{ARCHITECTURE OF THE JEDDAH SMART EMERGENCY RESPONSE SYSTEM}

Jeddah Smart Emergency Response System architecture is represented in:

- The Mission Control Center (MCC) which is built with MATLAB. MCC receives the help requests from smartphones, video cameras, and multiple sensors then create a tremendous amount of possible rescue scenarios via using the optimization algorithms and high-performance computing (HPC) such Aziz [17]. In order to generate the optimal action plan in seconds based on received data.

- Android-based smartphone application (ShAir): This allows survivors to submit help requests to the MCC from the disaster scene without the need for internet connection [18].

- $\quad$ Autonomous Vehicle and Aircraft: a fleet of drones, robots, biobots and unmanned aerial vehicles (UAVs) connects with MCC to conduct the mission plan which includes delivering the aids and instructions for help in dangerous areas for human intervention

- Communication Infrastructure which consists ad hoc network constitutes by drones and app that connects smartphones. This communication is a relay on User Datagram Protocol (UDP), Transmission Control Protocol (TCP).

- Simulink models and the 3D virtual world: which provides a realistic 3D visualization of the hardware elements such as any vehicles, drone, machine, or robot to prove they can operate correctly on disasters scenarios [19].

\section{JEDDAH SMART EMERGENCY RESPONSE SYSTEM OPPORTUNITIES}

The expected opportunities from (JSERS) are in line with the Saudi Vision 2030, which aims to develop the infrastructure and keep pace with global digital development [20]. These opportunities are representing in:

1. Make the city of Jeddah safer and improving the quality of life

2. Save lives, control damage to property and reduce time between incident occurring and response

3. Enables a real-time information sharing and simulation across wireless network

4. Attracts investors and investments in the telecommunications and information technology sectors

5. Enhances the fundamental competitiveness of the Saudi economy

6. Optimized resource planning and offer better citizen services

7. Create jobs: multidisciplinary such as public service experts; robot operators; drone operators; usability experts

8. Facilitate the governance of digital transformation through a national council

\section{JEDDAH SMART EMERGENCY RESPONSE SYSTEM CHALLENGES}

The challenges that are facing implement Jeddah Smart Emergency Response System (JSERS) lies in:

1. Availability of networks coverage and the Communication Infrastructure in the city of Jeddah.

2. Official policies are considered a national security issue which makes it inaccessible by the public or researchers.

3. Challenged to find the appropriate funds for short- and long-term project's objectives.

4. Slow adoption of new technologies.

5. Information security and privacy.

\section{IMPLEMENTATION}

The proposed system is complex, in phase one we have only implemented Jeddah emergency response application as a proof of concepts. The application designed to handle reporting incidents and get the most efficient and proper response by allow people in the affected area to submit help requests. Help requests could be relayed through people's devices via the application networks until drones hovering over the area picked it up to the mission control center. The requested items could be delivered by the direction of the mission control center. By using the application people could also share messages and pictures to increase situational awareness.

The proposed application allows affected people to share their situations using messages and pictures. It relies on relief requests from people in need to the mission control center. In addition it links the government services to each other and coordinate their collaboration. The interfaces are explained below 


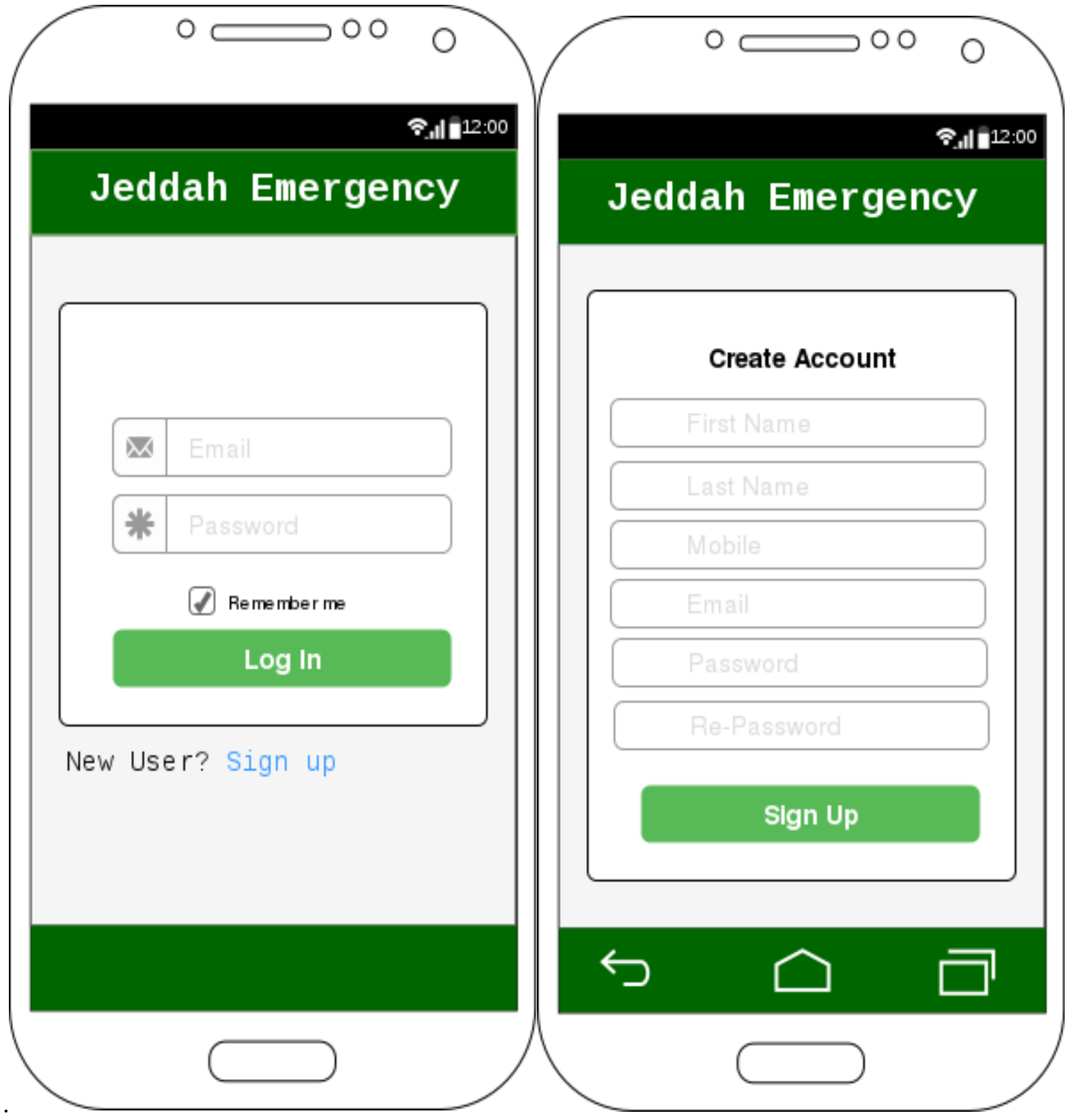

Figure1: login/ signup user interface

In figure 1 the two main interfaces of the application, where the user can sign in and creates an account. The name and phone number will be stored in government database to validate the information and handle the request formally by provide timely emergency response and make a link with the national ID/lqama. 


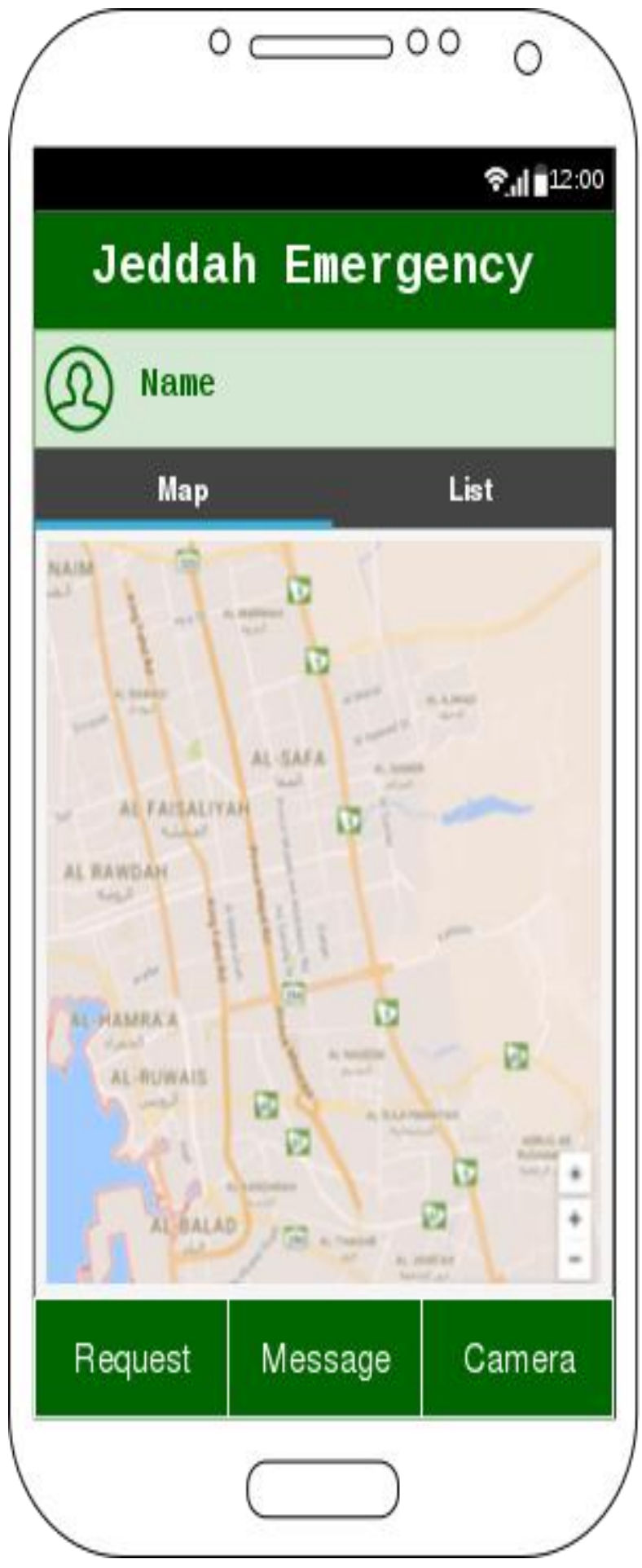

Figure2: Google map

As shown in figure 2, our application provide Google map in this interface. Google map is one of Google applications that provide very clearly traffic information by showing less traffic route with color of green and heavy traffic with color of red. And this will help the application to decide the decision that identifies the best route to reach the accident location. 


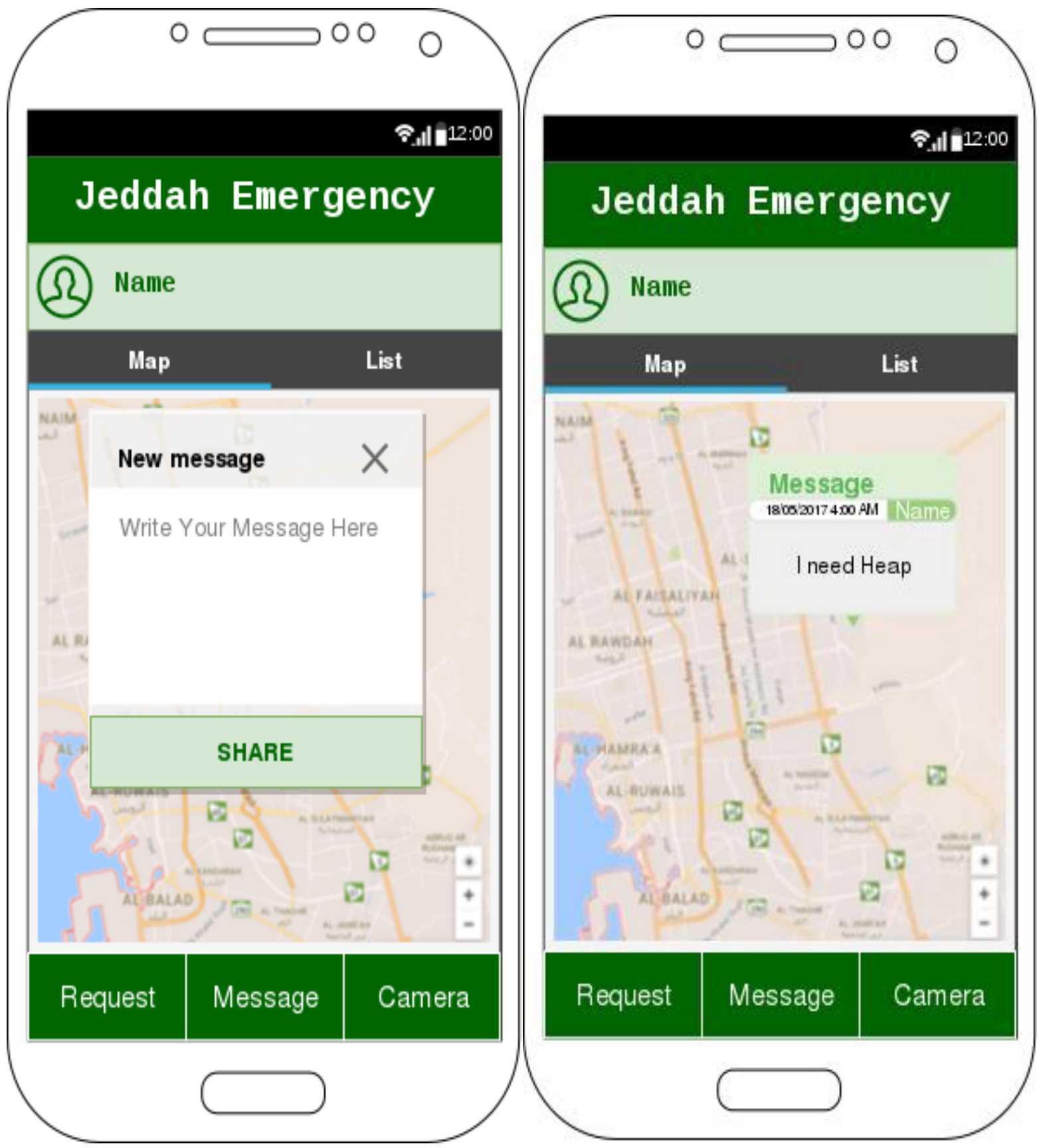

Figure3: user writes short message

Figure 3 illustrate an emergency scenario, the user can press message button to leave a short text message that will appear at the map with accurate information of his name and the time when he requested. This text message can describe the emergency case type, its state, or anything the user wants it to appear with his request. If there is not enough time to write or the user cannot, affected people can use the camera option, and send the picture of their situations to the Mission Control Center (MCC) linked with his/her information and location. 


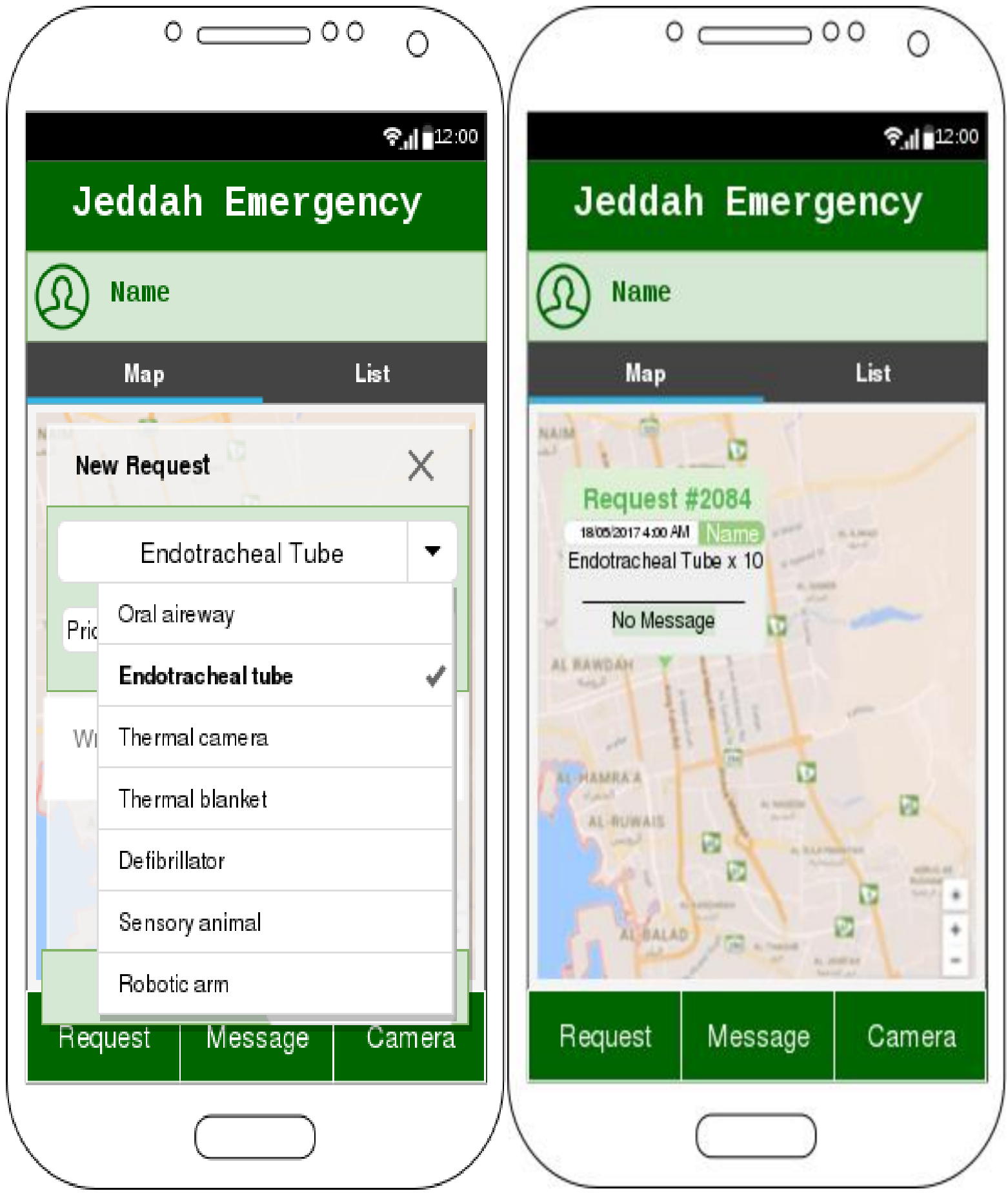

Figure 4: select emergency item and create request

When the user selects the Request button as shown in figure 4 can select from list items what he needs in an emergency case. For example when there is an accident and Injured who needs an endotracheal tube. The requested items will appear on the map with details like name and time. 


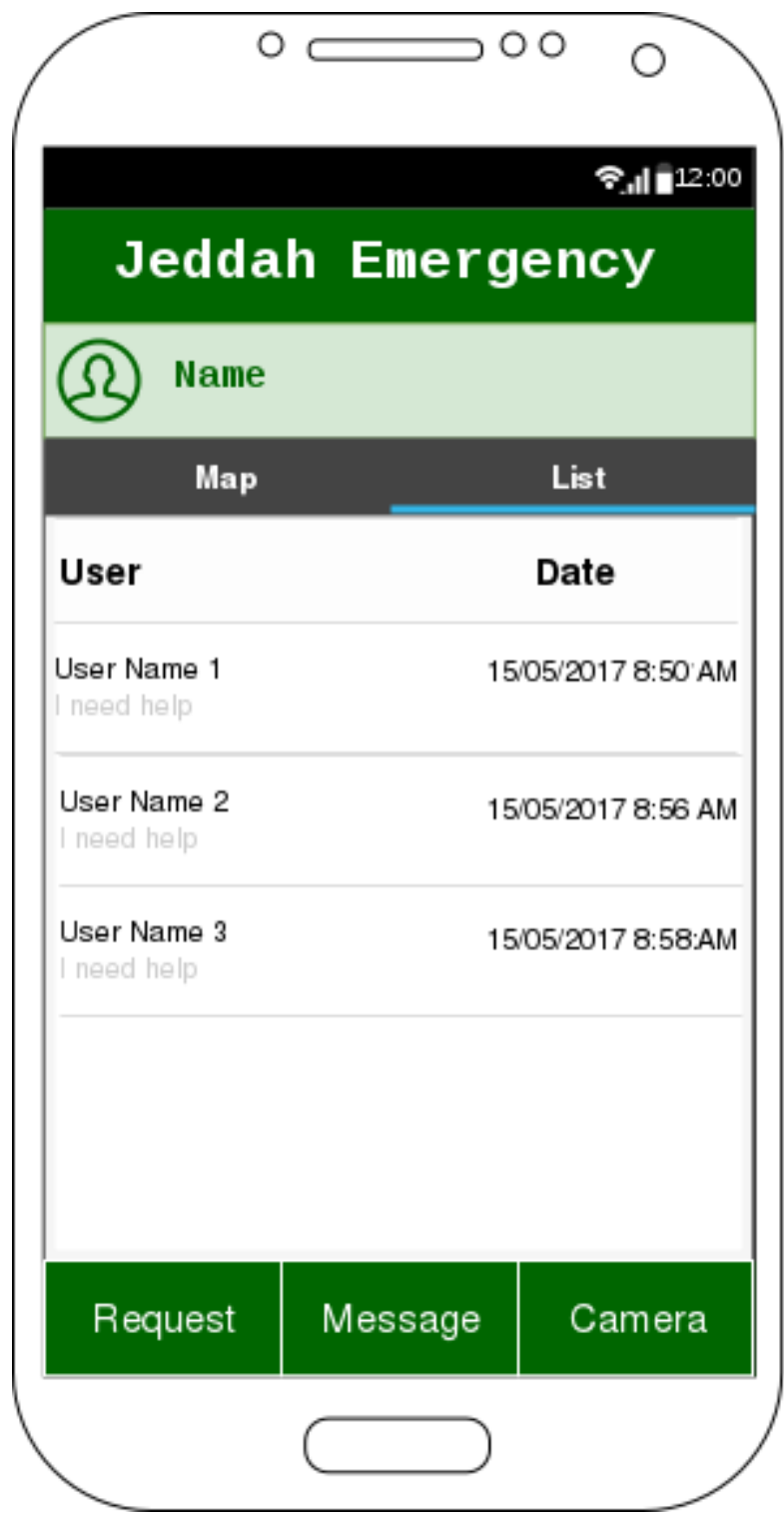

Figure 5: list of users need emergency response

As mentioned earlier the system deals with more than one sector. So, it would give priority on the first come, first serve basis for each sector. Figure 5 shows a list of users who need help from the civil defense sector which will treat the first user then the second and so forth.

\section{DISCUSSION}

In this section, we provide a set of suggestions that support the successful implementation and deployment of the proposed system. These suggestions are:

1. Provide robust, dynamic, and long-distance Wi-Fi communication infrastructure

2. Test and deploy various emergency scenarios, including flood, wildfire, terrorist attacks, and road traffic accidents

3. Analyze the performance in order to improve the emergency communication

4. Sets training plans and programs for JSERS's staff and follow-up the first responder capabilities

5. Educates Jeddah city community on JSERS's activities, operational procedures, and organization of work

\section{CONCLUSION}

During the last few decades, Jeddah city experienced frequent disasters that affected the people and country's resources. In addition, the current emergency response system in Jeddah still has the vulnerability. So, in this paper, we have proposed a Jeddah Smart Emergency Response System (JSERS) as a solution to improve the response to the emergency. In order to implement smart emergency response system based on experience-sharing and international expertise to minimize or element the effect of future disasters. We have provided this solution considering several experiences of the solutions 
deployments in the field of smart public safety and the ICT solutions that can be applied. This paper described the solution from the end users perspectives (phase 1), the following phase would be tackling the issue from the governmental

\section{REFERENCES}

1. Gartner Says Smart Cities Will Use 1.6 Billion Connected Things in 2016. (n.d.). Retrieved May 20, 2017, from http://www.gartner.com/newsroom/id/3175418.

2. Ghaffar, U. B., \& Ahmed, S. M. (2015). A review of road traffic accidents in Saudi Arabia: the neglected epidemic. Indian journal of forensic and community medicine, 2(4), 242-242.

3. 2015 Mina stampede. (2017, May 16). Retrieved May 20, 2017, from https://en.wikipedia.org/wiki/2015_Mina_stampede.

4. List of terrorist incidents in January 2017. (2017, May 18). Retrieved May 20, 2017, from https://en.wikipedia.org/wiki/List_of_terrorist_incidents_in_January_2017

5. Saudi arabia: 52 thousand fire incidents with 6 fires per hour. (n.d.). ArabianBusinessArabic.com . Retrieved April 2, 2017, from http://arabic.arabianbusiness.com

6. Abosuliman, S. S., Kumar, A., \& Alam, F. (2013). Disaster preparedness and management in Saudi Arabia: an empirical investigation. International Journal of Social, Human Science and Engineering, 7(12), 295-299.

7. Youssef, A. M., Sefry, S. A., Pradhan, B., \& Alfadail, E. A. (2016). Analysis on causes of flash flood in Jeddah city (Kingdom of Saudi Arabia) of 2009 and 2011 using multi-sensor remote sensing data and GIS. Geomatics, Natural Hazards and Risk, 7(3), 1018-1042.

8. Alamri, Y. A. (2010). Emergency management in Saudi Arabia: Past, present and future. Un. Of Christchurch report, New Zealand, 21.

9. Jadi, A. (2016). Improving the Emergency Services for Accident Care in Saudi Arabia. International Journal of Advanced Computer Science and Applications, 7(9). doi:10.14569/ijacsa.2016.070915

10. Pararas-Carayannis, G. CRITICAL ASSESSMENT OF DISASTER VULNERABILITIES IN THE KINGDOM OF SAUDI ARABIA-STRATEGIES FOR MITIGATING IMPACTS AND MANAGING FUTURE CRISES.

11. Yao, H., Liu, F., Zhang, L., \& Liang, D. (2013). Emergency Management System of Saudi Arabia. Procedia Engineering, 52, 676-680. doi:10.1016/j.proeng.2013.02.205

12. Abdulaal, M. (2014). Optimisation of Lagrangian Flash Flood Microsensors Dropped by Unmanned Aerial Vehicle (Doctoral dissertation).

13. Abdulaal, M., Algarni, M., Shamim, A., \& Claudel, C. (2014). Unmanned Aerial Vehicle based flash flood monitoring using Lagrangian trackers. In International Workshop on Robotic Sensor Networks.Baheti, R., \& Gill, H. (2011). Cyber-physical systems. The impact of control technology, 12, 161-166.

14. Baheti, R., \& Gill, H. (2011). Cyber-physical systems. The impact of control technology, 12, 161-166.

15. rolta. Smart \& safe cities: Concept to reality. 2015.

16. Zander, J., Mosterman, P. J., Padir, T., Wan, Y., \& Fu, S. (2015). Cyber-physical Systems can Make Emergency Response Smart. Procedia Engineering, 107, 312-318.

17. High Performance Computing Center. (2017, 8 27). Retrieved from King Abdulaziz University: http://hpc.kau.edu.sa/Default.aspx?Site_ID=611997\&Lng=EN

18. Object-Based Media Group, MIT Media Lab. (n.d.). A Platform For Mobile Content Sharing. Retrieved May 20, 2017, from http://shair.media.mit.edu/

19. Smart Emergency Response System. (n.d.). Retrieved May 20, 2017, from https://www.mathworks.com/campaigns/products/offer/smart-emergency-response-system.html.

20. Foreword. (n.d.). Retrieved May 20, 2017, from http://vision2030.gov.sa/en/foreword

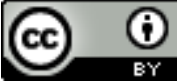

This work is licensed under a Creative Commons Attribution 4.0 International License. DOI:10.24297/ijct.v16i6.6323 